\title{
Correction to: User-dependent interactive light field video streaming system
}

\section{Bing Wang ${ }^{1} \cdot$ Qiang Peng ${ }^{1} \cdot$ Eric Wang $^{2} \cdot$ Wei Xiang $^{3} \cdot \mathrm{Xiao}_{\mathrm{Wu}^{1}}$}

Published online: 20 December 2021

๑) Springer Science+Business Media, LLC, part of Springer Nature 2021

\section{Correction to: Multimedia Tools and Applications (2021) https://doi.org/10.1007/s11042-021-11602-8}

The abstract in the original publication of this article contains spelling error, Tables 2 and 3 contain added data, and the phrase "with the proposed system" in the second line of the second paragraph of section 6 has to be removed. The original article has been corrected.

Publisher's note Springer Nature remains neutral with regard to jurisdictional claims in published maps and institutional affiliations.

The original article can be found online at https://doi.org/10.1007/s11042-021-11602-8.

\section{Bing Wang}

iceice_wang@outlook.com

1 School of Computing and Artificial Intelligence, Southwest Jiaotong University, Chengdu 611756, China

2 School of Science and Engineering, James Cook University, Cairns, QLD 4878, Australia

3 School of Engineering and Mathematical Science, La Trobe University, Melbourne, VIC 3686, Australia 